\title{
Providing Detailed Information on National Policies to Cope with the Covid-19 Pandemic
}

\author{
CHRISTOPHE GAIE, Direction Interministérielle du Numérique
}

This article considers the valorization of government interventions to support the economy in France; in particular, it provides a detailed geovisualization of emergency funds granted to companies. Transparency of the actions performed to cope with the pandemic situation is offered by the combination of open data and the usage of a new open-source visualization framework. It provides the essential information of public policies for citizens, academics, companies, public decision makers, and so on. The proposed framework is completely customizable and may be easily re-used in many crisis management situations, such as hurricanes, earthquakes, flooding, nuclear disasters.

CCS Concepts: • Applied computing $\rightarrow$ Computing in government; $\bullet$ Information systems $\rightarrow$ Open source software; - Human-centered computing $\rightarrow$ Visualization toolkits;

Additional Key Words and Phrases: Open government, open data, open-source algorithms, subsidies, public policies, economic subsidies, government intervention, transparency, visualization framework

ACM Reference format:

Christophe Gaie. 2020. Providing Detailed Information on National Policies to Cope with the Covid-19 Pandemic. Digit. Gov.: Res. Pract. 2, 1, Article 7 (November 2020), 11 pages.

https://doi.org/10.1145/3428089

\section{INTRODUCTION}

To cope with SARS-CoV-2, responsible for the infectious respiratory disease called Covid-19 h, almost every country around the world decided successively to enact a national lockdown. In the Europe Union, the lockdown was first decided in Italy on March 9, then in Spain on March 14, and on March 17 in France. This lockdown was held for more than two months with a very progressive economic recovery.

These decisions contributed to saving many lives, but they also triggered deep impacts on the economy. Assuredly, the interdiction for workers to reach their workplace reduced drastically some large parts of the real economy: construction, tourism, transports, retail, catering, and so on. Therefore national governments decided to grant many subsidies in order to minimize the economic impacts, especially on the smallest companies.

The author gratefully acknowledges its colleagues of DINUM/ETALAB, which provided the framework and developments. The author contribution is mainly focused on providing context, literature review as well as clarifying architecture concepts and describing public policies to support the economy.

Authors' address: C. Gaie, Direction Interministérielle du Numérique, 20 avenue de Ségur, Paris, France; emails: christophe.gaie@gmail.com, christophe.gaie@modernisation.gouv.fr.

Permission to make digital or hard copies of all or part of this work for personal or classroom use is granted without fee provided that copies are not made or distributed for profit or commercial advantage and that copies bear this notice and the full citation on the first page. Copyrights for components of this work owned by others than ACM must be honored. Abstracting with credit is permitted. To copy otherwise, or republish, to post on servers or to redistribute to lists, requires prior specific permission and/or a fee. Request permissions from permissions@acm.org.

(c) 2020 Association for Computing Machinery.

2639-0175/2020/11-ART7 \$15.00

https://doi.org/10.1145/3428089

Digital Government: Research and Practice, Vol. 2, No. 1, Article 7. Publication date: November 2020. 


\section{$7: 2$ - C. Gaie}

In France, the government decided to provide a solidarity fund to companies by engaging 7 billion euros. This help comes from the national stage as well as regions and relies on an emergency law referred to as Ordonnance n 2020-317 du 25 mars 2020. A particular mission ensured by DINUM/ETALAB consists in offering transparency about the allocation of these resources. To fulfill this essential mission, data visualization is an efficient solution to illustrate public policies. In the pandemic context, combining spatial visualization with specific data offers many advantages. First, it enables citizens to verify how subsidies are granted to companies in terms of amount, economic sector, geography, and so on. Then, it provides precise information to decision makers, which is essential to adjust public policies. For instance, it may be important to identify specific problems in a region or for a precise economic sector.

This may help to grant additional subsidies, which could be necessary to cope with the crisis of the culture sector. Finally, data visualization is a tool to communicate directly to companies on their rights and may be seen as an entrance door to other specific accompanying measures such as tax deferral or social charges reduction. This explains the importance of the open source framework proposed by French developers of DINUM/ETALAB.

In the literature, there exist multiple papers that describe the interest toward data geovisualization. Neuvel et al. [2011] propose a geographical framework to improve risk and emergency management. They underline the importance of information circulation between actors and propose both map and text visualization to ensure that the information may be understood by every involved actor. Although their approach is really valuable, it relies on a specific system, entitled Eagle, which is not directly reusable by external entities. Furthermore, the architecture of this system is rather complex as it relies on 12 modules gathered in four blocks.

Another interesting example of geovisualization ${ }^{1}$ was proposed in Enders and Brandt [2007]. In this article, the authors highlight the importance of Geographic information systems (GIS) technology to coordinate resources from separate systems during a crisis. This coordination aims to provide a specific response to help people in a situation of disability (i.e. persons with physical or mental impairments). Their research underlines the importance to establish the link between people needs and available resources. To reach this objective, the authors detail a case study that illustrates an efficient combination of data from national government, local authorities, and non-profit sectors. This combination of data should be anticipated and requires us to standardize data repositories for further usage. The proposal of the current article aims to provide a framework to facilitate this kind of data juncture.

The current article is organized as follows. Section 2 provides a review of the literature concerning open data in administrations and measures to support the economy in the context of Covid-19 and open-source frameworks to facilitate data visualization. Then, Section 3 describes a process that can be used to open data. Thereafter, Section 4 depicts the measures taken by the French government to support the economy, while Section 5 details the framework used by the DINUM/ETALAB developers to illustrate the public policy. Next, Section 6 provides illustrations and explanations that rely on the data opened and the framework developed. Finally, Section 7 concludes this article by a recap of the proposals and perspectives for future work.

\section{LITERATURE REVIEW}

The review proposed tackles the three directions tackled by the current article: (1) The importance of Open Data for public services, (2) the measures adopted to mitigate the effects of the pandemic on the economy, and (3) the existing visualization frameworks to illustrate public policies as well as their outcomes. Open data is a significant issue to follow the efficiency of public services as well as their transparency. Open data may also generate innovation, as startups may combine information about transports, ecology, energy, and buildings to provide new services. Actually, the increase of data produced is directly connected to the dematerialization of administrative processes and the digitalization of the economy. Every day we can observe the exponential

\footnotetext{
${ }^{1}$ Geovisualization consists in representing simultaneously and at the same location some elements and their related data.
}

Digital Government: Research and Practice, Vol. 2, No. 1, Article 7. Publication date: November 2020. 
growth of exchanges among citizens, companies, and public services. To deal with the tremendous amounts of data, governments should structure them and ensure public access that is as large as possible.

Davies [2010] provides a large analysis on the usage of data and on the functioning of Data.gov.uk. Indeed, the data produced may provide information, reused from another purpose, combined with different data, and so on. The author also provided a survey of the usage of their data (small businesses and public agents) as well as their various objectives. The research is highly instructive but does not provide any concrete proposal to improve the opening of data, as it mainly relies on conceptual orientations.

Bauer and Kaltenböck [2011] underlined the importance of the memorandum for transparency signed by Barack Obama in January 2009. This decision gave political and decisive support to the emergence of open data. Moreover, they recall the 8 principles for Open Government Data set in 2007 in Sebastopol, California, which became 10 in 2010 with the Sunlight expansion. Above all, the authors insisted on the importance of linking data to provide valuable data. The guide addresses this link from both sides: the publisher and the consumer. The authors propose a 5 Stars Model to evaluate the degree reached by an organization in the Open Data perspective. They also illustrate how linking open data is powerful using a cloud diagram. Although the work performed is remarkable, it remains at a conceptual level.

Martin et al. [2013] propose a method to identify and overcome the barriers that limit the emergence of egovernment. Their research relies on three use cases with various scale: a medium city in France, a large city in Germany, and the United Kingdom as a national scale. The analysis provided details the limitations observed as well as the new opportunities for multiple categories: governance, economy, lawfulness, and so on. The illustration notably hinges on a synthetic Ishikawa diagram and further additional information. The mitigation measures proposed are really useful for deciders in charge of data opening. Remarkably the amount dedicated by the French government to open data is more than the double that of the United Kingdom. Whereas this research provides noteworthy results, it does not propose a concrete implementation that would reduce the barriers to facilitate the opening of data.

In the current context of the Covid-19 pandemic, countries adopted various measures to reduce the impact of the crisis on poverty, unemployment, and, more generally, the economy. For instance, Lord [2020] compares two main actions of North American governments (especially Canada) to enlarge the access to unemployment insurance or provide subsidies to companies. This study relies on the availability of data concerning unemployment in every sector to propose fair public policies. These data are as follows: the unemployment rate, the unemployment per sector of activity, the mean salary of workers, the evolution of unemployment, salaries and Gross Domestic Product, and so on. Thus, the author is able to outline that measures are efficient to outline the importance of the crisis but do not seize all its complexity, as some people with no work are not considered as unemployed as they cannot look for a job during the pandemic. Moreover, the author points out an unfair situation, since people with no insurance are granted subsidies, whereas workers who have unemployment insurance are not. Then, the author proposes to grant subsidies to companies in order to keep workers on payroll. Finally, he underlines the importance of controlling the amount of money delivered to limit the impact on the government debt. All these operations require to combine data in a dashboard that will enable to manager the response to crisis.

The analysis provided in Vanini [2020] details the different measures adopted by countries to support their economies. These measures essentially rely on injecting money with Quantitative Easing (QE) or Targeted Longer-Term Refinancing Operations (TLTRO). Measures can also consist in granting loans to companies in order to keep the workforce as well as pay for fixed costs (renting of buildings, maintenance costs, capital costs, etc.). This strategy is crucial to provoke a bouncing effect at soon as the lockdown is over. The article details the considerable efforts of some countries (10.9\% of GDP in the USA, $17.5 \%$ in Germany, $14 \%$ in France) in comparison to others ( $0.4 \%$ in Japan, $5.7 \%$ in China, $3.3 \%$ in Canada, etc.). The objective is to avoid a domino effect where the bankruptcy of some companies endangers others, and so on. The reader should notice that this remarkable comparison could only be achieved thanks to the data opened by every cited government. 
The third topic addressed in the current literature review refers to the visualization frameworks available to spatially represent public policies or any other information. A framework based on HTML5 was proposed in Mao et al. [2012] to enable spatio-temporal visualization. This framework relies on a database that stores data and is linked to spatio-temporal information by a Jetty WebServer. The data are acquired using WebSocket with a JavaScript program, and data are mashed up with Google Maps into the browser. This framework could be used to follow the movement of volunteers using GPS tracking. However, the article only describes the architecture of the solution, and the source code is not provided, which prohibits any reuse.

Another approach for geovisualization was proposed in Zichar [2012]. The authors propose to use Keyhole Markup Language (KML) to visualize different agriculture elements such as objects (e.g., fields, forests), events (e.g., irrigation, spraying crops), processes (e.g., floods, forest fire), and so on. A popular implementation of KML was Google Earth Maps, but the language is presently a standard validated by the Open Geospatial Consortium and whose specification is available at the following location: https://www.ogc.org/standards $/ \mathrm{kml} /$. The article highlights different usage of KML in the context of agriculture or simple geovisualization but does not use it for a concrete purpose. It is important to underline that ETALAB publishes data in multiple formats including KML, GeoJSON, and Shapefile (see, for example, the publication of data concerning inter-communal structures, https://www.data.gouv.fr/fr/datasets/epci-2017/).

The importance to make the link between open data and its outcome was detailed in multiple publications. For instance, Ruijer et al. [2017] developed a model to monitor democratic activity of open data. Their proposal analyzes three democratic processes: (1) monitorial, which relies on a mandate given by people to the government to build the law and ensure its application; (2) deliberative, which consists of organizing public debates and taking into account the decision process; and (3) participatory, where citizens may actively engage to build laws and provide solutions to societal problems. To analyze their model, the authors detail three case studies and their outcomes. The first case study underlines that in a monitorial democracy, open data increases confidence granted to the administration. The second case study illustrates that open data contributes to improve the quality of debate. The last case study shows that open data improves the collaboration process of law creation, as it relies on objective information.

Mergel et al. [2018] propose interesting material on the outcomes of open data. The authors underline that open data provides much more than the mere transparency on the public sector interventions. Indeed, they propose a typology of outcomes that may be internal or external and relies on the process or the product. This analysis offers better perspectives for data valorization, as the outcomes impact multiple dimensions. A similar investigation may be applied to the framework proposed in this article. This also provides multiple outcomes: (a) internal processes are improved, as the data geovisualization gives comparative information on regions; (b) internal products are facilitated, as any region may obtain detailed information on its action; (c) external processes are upgraded, as data may be reused by private actors to provide rebound strategies; and (d) external products have increased value, as the framework simplifies data access.

Finally, the combination of geovisualization and storytelling proposed by in Ho [2013] deeply improves the impact of data publication. Indeed, the authors propose to combine multiple illustrations of a same phenomenon to offer a more complete user experience. Thus, their proposal relies on HTML5-based geovisual analytics tools thatenables us to provide simultaneously multiple statistics charts as well as their literal explanations. The proposed framework relies on a simple click button that permits to publish the meaning of data observed during the interactive discovery process. The simultaneous publication of data and explanations offers large reuse perspective in the context of Open Data, since it is easier to reuse contextualized information than raw data.

\section{A PROCESS TO PROVIDE OPEN DATA}

In the current context of Covid-19, data opening aims to highlight the support to the economy ensured by the government. In this section, the authors details how the agile philosophy of DINUM/ETALAB matches perfectly with the the process proposed by Villazón-Terrazas et al. [2011] to provide open data. Their proposal relies on

Digital Government: Research and Practice, Vol. 2, No. 1, Article 7. Publication date: November 2020. 


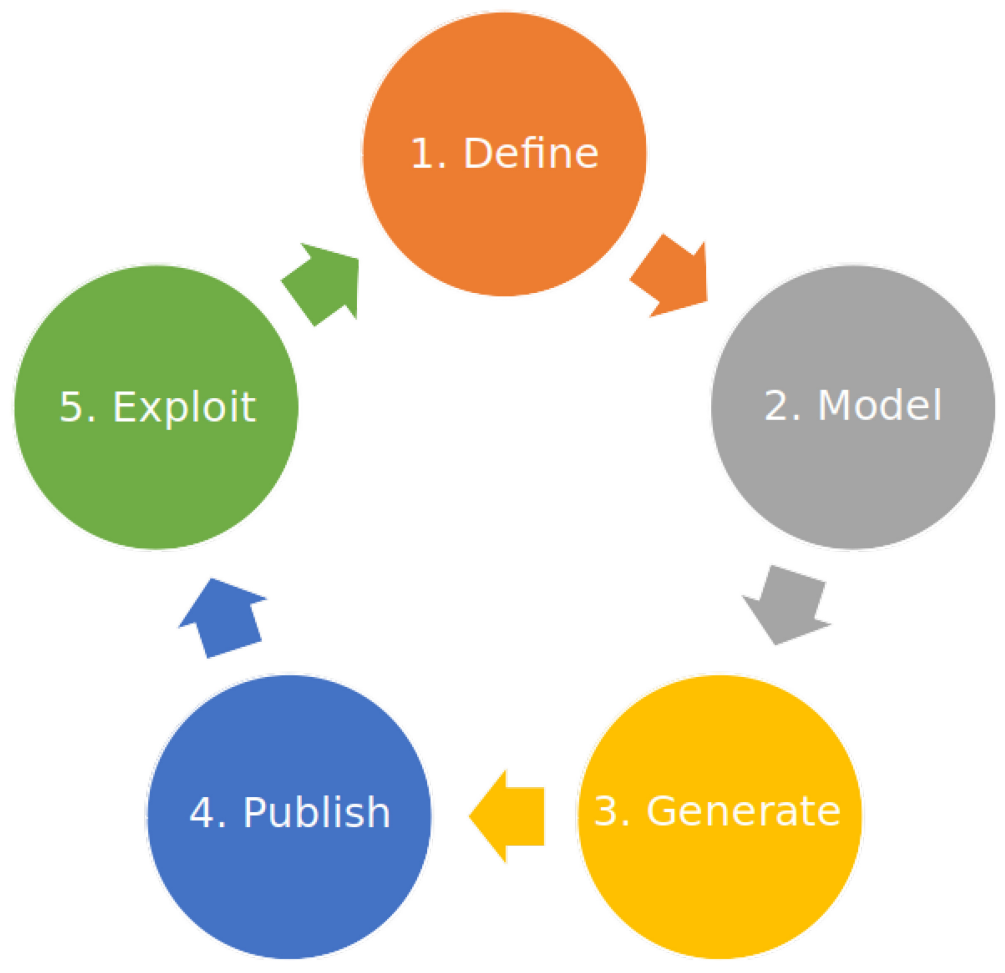

Fig. 1. A model to provide open data.

a circular process that fits agile development principles. To facilitate the understanding, the model is adapted to the context in the rest of this section. Figure 1 details the different steps required to open data and, after a first production run, how to expand it to new data.

Before explaining how the different tasks are performed, it is necessary to identify the different actors:

a) Deciders are the government and related services. They need simple schemes to illustrate their communication to citizens.

b) Project team corresponds to the IT services in charge of opening data (ETALAB in the context). This team is directly related to deciders in order to ensure project commitment.

c) Contributors are the IT services that provide access to raw data (services from the Ministry of Finances). They should guarantee the meaning, value and coherence of data.

To achieve this objective, the roles played by the different services are defined as follows:

1. Define: The communication on public policies is set by deciders, in compliance with the law. They determine which data should be public and the project teams has to identify where to find them (identify raw data). Each identified contributor has to provide them, preferably in accordance to the model chosen. This step also aims to define which type of license will be used. ETALAB uses the Licence Ouverte/Open License detailed here: https://www.etalab.gouv.fr/licence-ouverte-open-licence.

2. Model: The project team and contributors have to define which data to extract and how to structure them. They should define a simple exchange format such as JSON or CSV that facilitates the combination of multiple sources and decouples the production of data (back-end) from their usage and display (front-end). The frequency of publication and the storage repository should also be decided. In the current context, 
a daily vision is adapted to the objectives, and the data are stored by ETALAB, which ensures its further transformation.

3. Generate: The data are produced by each contributor and transmitted to the project team fulfilling the commitments previously established. They are stored on a particular folder accessible to every interested person (citizen, company, public organization, etc.) on the website of ETALAB. ${ }^{2}$ This structured data are then processed to link economic information in a database. This process is described in Section 5 of the article.

4. Publish: the database information is combined with the visual framework to provide different viewpoints of subsidies delivered to companies. The main illustrations are an open map of subsidies by region or department, a pie chart of the subsidies according to the company size, and a histogram of subsidies depending on economic sector. These illustrations are detailed in Section 6 of the article. A dedicated URL was chosen to enable a specific access to visualize the governmental actions: https://aides-entreprises.data.gouv.fr/.

5. Exploit: the data and illustrations should be accessible at any time and from everywhere. Thus, the solution chosen relies on daily updates where the new data are appended in a new folder (backend/json/aides/fdsYYYY-MM-DD). Moreover, the existing data (JSON files) are only replaced if the new one is available. The functioning is detailed on a public repository: https://github.com/etalab/dashboard-aides-entreprises.

Obviously, this process poses multiple risks of fraud, as described in OECD [2018]. Some typical risks are described thereafter:

- Underdeclare information to obtain subsidies. This fraud is easily detected and should not operate, as there are basic first-level controls using known information about companies.

- Impersonate another company identity or bank details to steal money. This type of fraud is more complex and often relies on social engineering attack to obtain information on a target company. A warning sign may appear when a company suddenly modifies its bank details. This should lead to a verification prior to the grant payment.

- Hijack subsidies by creating new phantom companies. This fraudulent behavior could be avoided by excluding companies created during the pandemic as well as companies with no turnover.

\section{SUPPORTING COMPANIES IN FRANCE}

As explained in the Introduction, the French government set up an emergency fund of 7 billion euros to support the economy. The current section describes the guidelines chosen to allocate money to companies. This description helps us to analyze the allocation of resources illustrated by maps in Section 3. Thus, the allocation is granted by the French Tax administration according to transparent criteria. The process relies on two successive steps:

1. The officer of the company fills an electronic form using the secured software provided by the government.

2. The French Tax Administration verifies the claim according to data it possesses from previous tax reports. It also takes into account the reliability of new information. Figure 2 illustrates the core of the decision process.

a) The first criterion of eligibility aims to verify the company characteristics, since the objective is to provide help to the smallest firms.

b) Then, firms affected by the confinement should obtain subsidies, which explains the second criterion.

3. For each accepted claim, the French Tax Administration transfers money from the national budget to the company after ensuring some usual payment verifications (bank account, fiscal regularity, and so on). If the claim is refused, then the company is invited to claim a specific sate guaranteed loan to banks.

\footnotetext{
${ }^{2}$ The exact URL is https://www.data.gouv.fr/fr/datasets/donnees-relatives-au-fonds-de-solidarite-mis-en-place-dans-le-cadre-delepidemie-de-covid-19/.
}

Digital Government: Research and Practice, Vol. 2, No. 1, Article 7. Publication date: November 2020. 


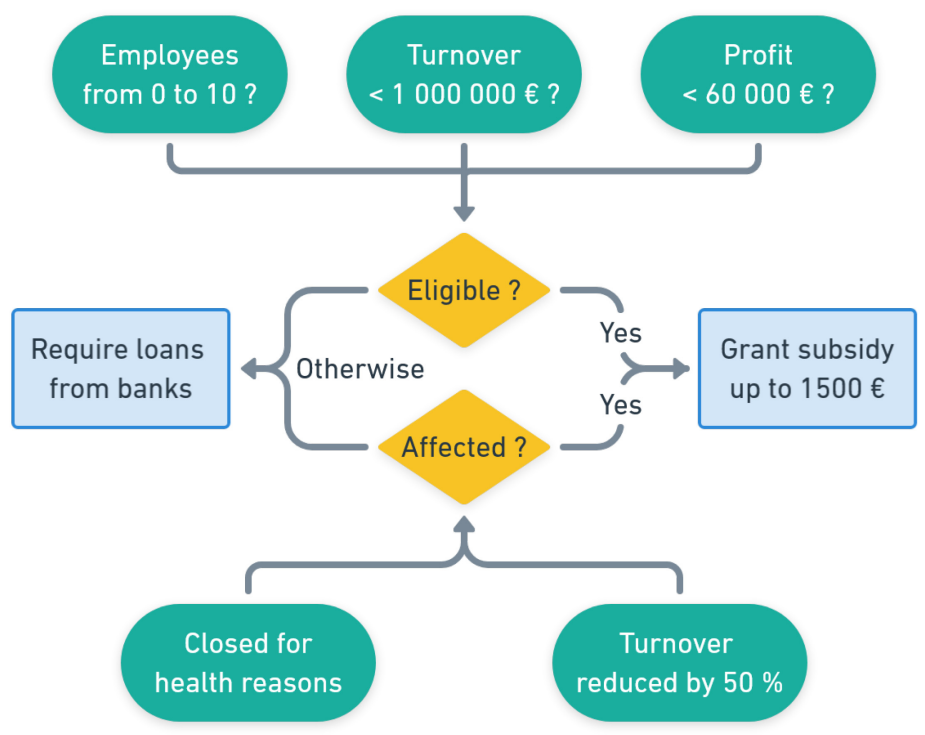

Fig. 2. Decision process to grant subsidies at the national level.

The detection of these frauds relies on the expertise of the French Tax Administration, which recently developed many tools to improve data usage. The French Government also decided to set up a second aid to help companies that suffer from specific financial difficulties relied to the Covid-19 pandemic. The functioning is described thereafter:

1. The officer of the company fills another electronic form using the secured software provided by the region.

2. The services of each region verify the claim according to data they possess. It also takes into account the reliability of new information. Figure 3 illustrates the core of the decision process.

3. If the criteria are fulfilled and the demand is validated by the region services, then the Tax Administration is notified of the payment decision.

4. For each accepted claim, the French Tax Administration transfers money from the region to the company after ensuring some usual payment verifications (bank account, fiscal regularity, and so on). If the claim is refused, then the company is invited to claim a specific sate guaranteed loan to banks.

It is important to underline that each datum or decision described in this section is confidential. The next section describes how to fulfill the transparency on the public policy of national solidarity.

\section{BUILDING A MODULAR ARCHITECTURE TO FACILITATE GEOVISUALIZATION}

In order to visualize the effort of the government to support companies, ETALAB developed a new framework that relies on the following:

1. Raw Data, which is transmitted by different government administrations in charge of companies, unemployment, statistics, tax recovery, and so on.

2. Structured Data, which is obtained by data processing that enables us to fill in a PostgreSQL database.

3. Prepared Data, which consists of data in a format compatible with geovisualization.

4. Geovisualized Data, which consists of data exposed on a map. 


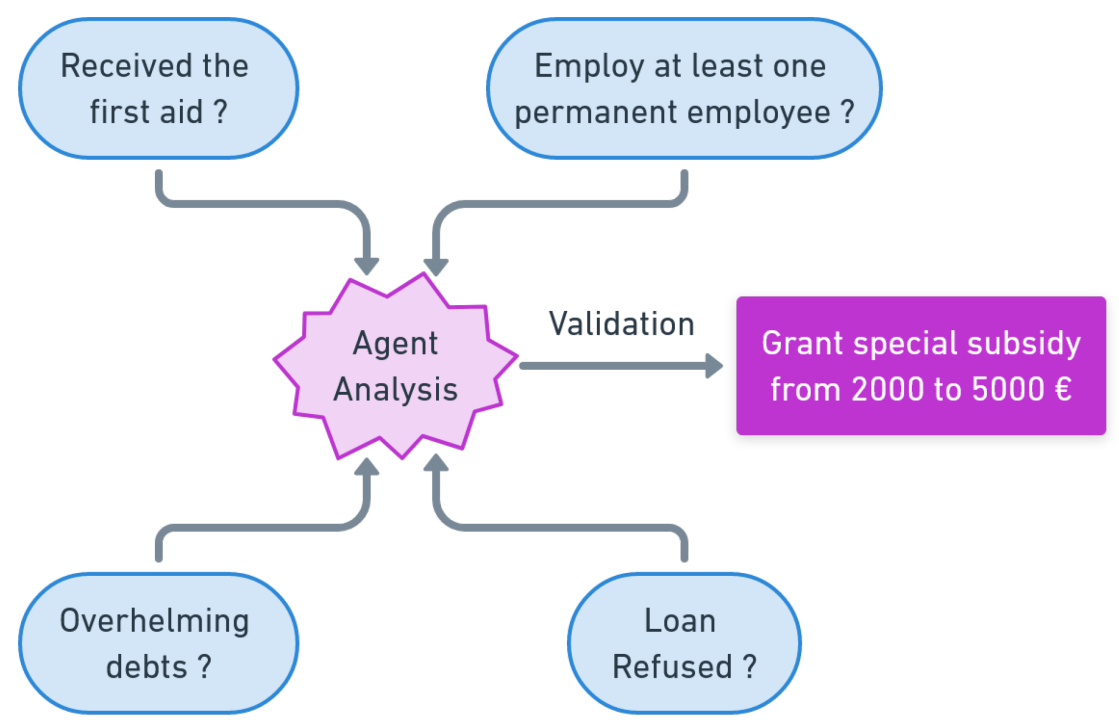

Fig. 3. Decision process to grant subsidies at the regional level.

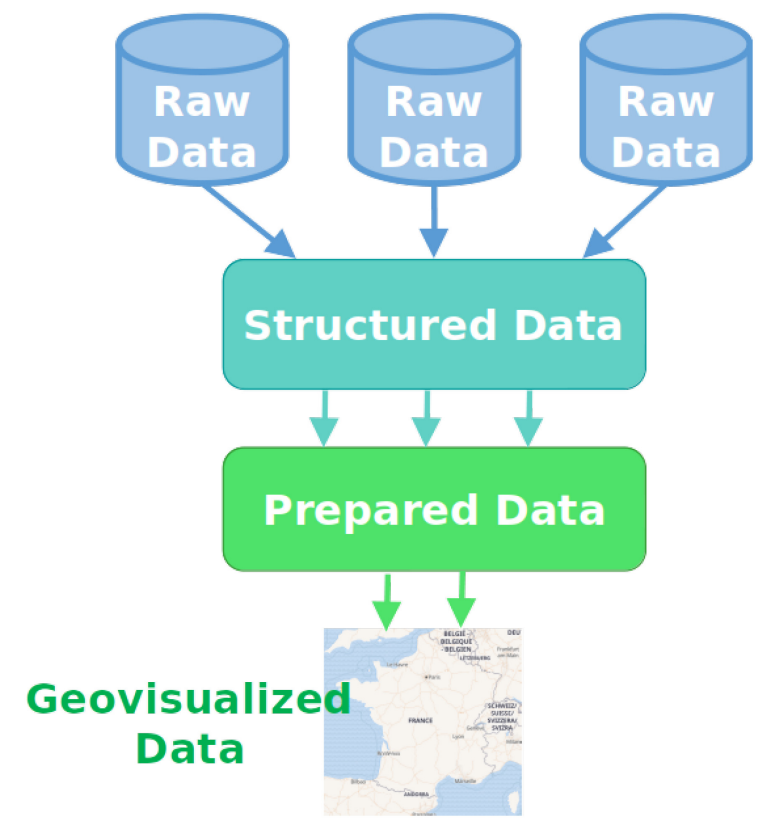

Fig. 4. Description of the geovisualization framework.

Figure 4 illustrates the propsed architecture. Although detailed explanations on ODAMAP are proposed at https://etalab.github.io/dashboard-aides-entreprises/general/overview/, the author underlines the attractive features of involved components:

1. Reactivity of display is ensured by using Single-Page Application principles. Indeed, the front-end code is developed with the framework Vue.js/Nuxt.js and relies on a Client-Side Rendering. 
Table 1. Simulation Configuration

\begin{tabular}{|c|c|c|c|}
\hline Column FR & Type & Description EN & Example \\
\hline dispositif & String & main fund name & Solidarity fund \\
\hline volet & String & funding component ID number & Segment 1 \\
\hline nombre_aides & String & number of assigned fundings & 1397 \\
\hline montant_total & String & total amount of assigned fundings & 21191.00 \\
\hline reg & String & geographical region ID number & 84 \\
\hline dep & String & geographical sub-region ID number & 43 \\
\hline libelle_region & String & geographical region name & Auvergne Rhone Alpes \\
\hline code_section & String & NAF code section (business sector) & S \\
\hline libelle_section & String & NAF section name (business sector) & Other activities \\
\hline
\end{tabular}

2. Plurality of visualizations, which may combine map views (with Mapbox-GL) and chart views (with ApexCharts) using iframe integration possibility.

3. Adaptability is provided by the usage of mobile responsive design and the possibility to load external content like text/html or provide routable URLs (routes and URL parameters).

4. Data aggregation as the framework allows us to display several datasets (locally from statics or distant).

\section{ENSURING TRANSPARENCY ON THE FUNDS USAGE}

As the amount of money granted by national and regional services is tremendous, the importance of ensuring the total transparency on the funds usage is crucial. Thus, ETALAB ${ }^{3}$ published many national maps to detail precisely which types of companies benefited from subsidies depending on their localization.

Every day, the data are published automatically on the URL https://aides- entreprises.data.gouv.fr/ and may be visualized using OpenStreetMap 4. Table 1 describes the model used to provide open access to national subsidies accorded to companies. The developed framework is entitled ODAMAP ${ }^{4}$ and is illustrated thereafter.

The data published enable us to illustrate different information and provide transparency on the government intervention. The following paragraphs detail some possible illustrations.

An important point of view consists in illustrating the amount of money delivered by region and detailing this allocation by sector of activity. This information is really important for the government, as it contributes to the global vision of the pandemic consequences. It also facilitates communication on the economic actions performed to overcome the crisis. As of August 28, 2020, the global amount of subsidies granted in France reached 5.775 million euros.

Figure 5 provides detailed information on the allocation of subsidies within the Britany region. This enables the local authority to obtain precise information on the amount of money delivered to each department. It also permits us to detail this allocation by sector of activity. In the example provided, Britany decision makers obtain immediate information on the amount of money granted (216 million euros), the number of subsidies $(162,000)$, and the number of companies targeted $(70,000)$. They also obtain detailed information on the sector supported to cope with the crisis (catering, retail, and healthcare) and the amount of money delivered to various sectors (22 million euros). Thus, they may want to refine this information to identify precise sectors and propose specific measures if necessary.

The reader should also notice that the information on the department could also be detailed. On the contrary, it was chosen to exclude detailed information on cities, as this would destroy anonymity in some situations (there exist some villages with fewer than 100 inhabitants). The framework also enables us to provide information about

\footnotetext{
${ }^{3}$ Within DINUM, ETALAB is the IT service dedicated to the publication and valorization of data.

${ }^{4}$ OpenStreetMapÂ ${ }^{\circledR}$ is a repository of opendata that is available in the Open Data Commons Open Database License.
} 


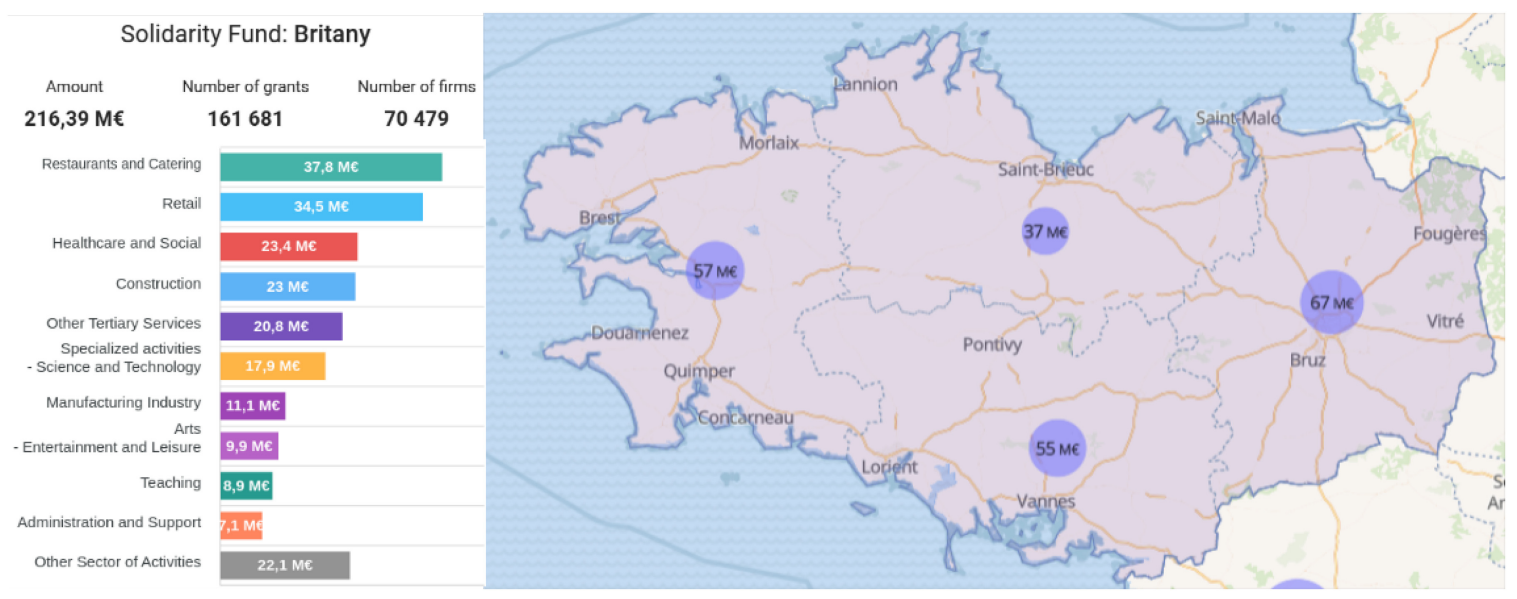

Fig. 5. Overview of the distribution of subsidies between in a particular region.

any country around the world. A simple illustration on a wider scale enables us to outline subsidies granted to overseas department such as:

- Atlantic Ocean Area: La Guadeloupe, La Martinique, La Guyane

- Indian Ocean Area: Mayotte, La Runion

\section{CONCLUSION (AND PERSPECTIVES)}

This article provides multiple contributions to improve e-government policies in the context of the Covid-19 pandemic. The examples of the French government action are described to illustrate the research.

First, a review was performed to tackle the topic of illustrating the actions of governments during the Covid19 pandemic. Three dimensions were depicted: the importance of open data for public services, the measures adopted to mitigate the effects of the pandemic on the economy, and the existing visualization frameworks to illustrate public policies.

Then, the author proposed a general process to structure data and enable their reuse by any researcher, citizen, company, and so on. The steps to examine and compute subsidies granted to companies is also detailed to ensure transparency of the public policy.

Finally, the open-source framework proposed by the French Prime Minister services (DINUM/ETALAB) is detailed, since its functioning may be reused in multiple contexts. A simple connection to the website provided by the French Ministry of Finances show new usages for this framework (fiscal deferral, grants to self-employed workers, partial unemployment).

The outcomes of the framework are multiple and local decision makers largely rely on it to adjust their public policies. Indeed, it enables them to compare the subsidies granted by similar regions more easily than by comparing legal documents.

Further research should describe the reuse performed to provide new grants and/or to tackle new topics in the context of a economic recovery strategy (also entitled Stratgie de rebond conomique). Another improvement of the framework could be to offer a time-based illustration of subsidies highlight the time to deliver money and minimize it for better efficiency.

Digital Government: Research and Practice, Vol. 2, No. 1, Article 7. Publication date: November 2020. 


\section{ACKNOWLEDGMENTS}

The author gratefully acknowledges DINUM / ETALAB, which provided the framework and developments. The author contribution is mainly focused on providing context and literature review, as well as clarifying architecture concepts and describing public policies to support the economy.

\section{REFERENCES}

Florian Bauer and Martin Kaltenböck. 2011. Linked open data: The essentials. Retrieved from https://www.semantic-web.at/LODTheEssentials.pdf.

Tim Davies. 2010. Open data, democracy and public sector reform: A look at open government data use from data.gov.Uk. Practical Participation. Retrieved from http://practicalparticipation.co.uk/odi/report/wp-content/uploads/2010/08/How-is-open-government-data-beingused-in-practice.pdf.

A. Enders and Zachary Brandt. 2007. Using geographic information system technology to improve emergency management and disaster response for people with disabilities. F. Disabil. Policy Stud. 17, 4 (2007), 223-229.

Quan Ho. 2013. Geovisual analytics framework integrated with storytelling applied to HTML5. In The 16th AGILE International Conference on Geographic Information Science: Geographic Information Science at the Heart of Europe. Retrieved from https://www.diva-portal.org/ smash/record.jsf?pid=diva2\%3A618037\&dswid=3646.

Phil Lord. 2020. Incentivising employment during the COVID-19 pandemic. Theory Pract. Legisl. (2020), 1-18. DOI : https://doi.org/10.1080/ 20508840.2020 .1792635

Bo Mao, Zhian Wu, and Jie Cao. 2012. A framework for online spatio-temporal data visualization based on HTML5. Int. Arch. Photogram. Remote Sens. Spatial Inf. Sci. XXXIX-B2, 07 (2012), 123-127. DOI : https://doi.org/10.5194/isprsarchives-XXXIX-B2-123-2012

Sébastien Martin, Muriel Foulonneau, Slim Turki, and M. Ihadjadene. 2013. Risk analysis to overcome barriers to open data. Electr. f. E-Gov. 11, 01 (2013), 348-359.

Ines Mergel, Alexander Kleibrink, and Jens Srvik. 2018. Open data outcomes: U.S. cities between product and process innovation. Gov. Inf. Quart. 35, 4 (2018), 622-632. DOI : https://doi.org/10.1016/j.giq.2018.09.004

J. M. M. Neuvel, H. J. Scholten, and A. van den Brink. 2012. From spatial data to synchronised actions: The network-centric organisation of spatial decision support for risk and emergency management. Appl. Spatial Analysis 5 (2012), 51-72. DOI : https://doi.org/10.1007/s12061010-9059-z

OECD. 2018. Tax administration: Privacy, disclosure and fraud risks related to COVID-19. OECD Policy Responses to Coronavirus (COVID19) (26 5 2018). http://www.oecd.org/coronavirus/policy-responses/tax-administration-privacy-disclosure-and-fraud-risks-related-tocovid-19-950d8ed2/.

Erna Ruijer, Stephan Grimmelikhuijsen, and Albert Meijer. 2017. Open data for democracy: Developing a theoretical framework for open data use. Gov. Inf. Quart. 34, 01 (2017). DOI :https://doi.org/10.1016/j.giq.2017.01.001

Paolo Vanini. 2020. Protection of the population and the economy in a pandemic. (2020), 1-21. (unpublished).

Boris Villazón-Terrazas, Luis. M. Vilches-Blázquez, Oscar Corcho, and Asunción Gómez-Pérez. 2011. Methodological Guidelines for Publishing Government Linked Data. Springer, New York, NY, 27-49. DOI : https://doi.org/10.1007/978-1-4614-1767-5_2

Marianna Zichar. 2012. Geovisualization based upon KML. F. Agric. Inf. 3.06 (2012), 19-26. DOI : https://doi.org/10.17700/jai.2012.3.1.49

Received July 2020; revised August 2020; accepted October 2020 